\title{
PERIODIC CURRENT OSCILLATIONS AT THE GOLD/ACID AQUEOUS INTERFACES INDUCED BY $\mathrm{HCl}$ ADDITIONS
}

\author{
J. J. Podest A, R. C. V. Piatti and A. J. Arvia \\ Instituto de Investigaciones Fisicoquímicas Teóricas y Aplicadas, División Electroquímica, \\ Sucursal 4, Casilla de Correo 16, 1900 La Plata, Argentina
}

(Received 13 June 1978; in revised form 10 December 1978)

\begin{abstract}
The periodic oscillating current recorded under a constant potential step for Au/acid solution interfaces containing different concentrations of $\mathrm{Cl}^{-}$ion is studied in the $25.50^{\circ} \mathrm{C}$ range. Two main electrochemical reactions coupled to two diffusion processes are responsible for the periodic effect. The electrochemical reactions occurring successively are the electrodissolution of gold as the AuCl${ }_{2}^{-} \mathrm{complex}_{\text {, a }}$ reaction which is diffusion controlled and then the oxide layer formation when the solution is depleted of $\mathrm{Cl}^{-}$ ion. Subsequently, as the anodic current decreases due to the electrode passivation, the $\mathrm{HCl}$ diffuses backwards and dissolves the oxide film. The active part of the periodic cycle is interpreted in terms of a difusional process involving at its initiation the simultaneous uncoverage of the electrode surface.
\end{abstract}

\section{INTRODUCTION}

The electrochemical response of the Au/acid aqueous interface depends to a large extent on the type of anions prevailing in the solutions. In this respect the electrochemical behaviour of gold both in diluted and in sulphuric acid containing different amounts of hydrochloric acid are different[1-13]. It should be pointed out that the reaction product in the absence of $\mathrm{HCl}$ is an aquogold complex while in $\mathrm{HCl}$ containing solutions are the chloro-gold complexes. Probably the passivity region is influenced by the characteristics of the oxide film which are most likely functions of potential and $\mathrm{Cl}^{-}$ion concentration. The kinetic information of the two independent systems, namely $\mathrm{Au} / \mathrm{HCl}(\mathrm{aq})$ and $\mathrm{Au} / \mathrm{H}_{2} \mathrm{SO}_{4}(\mathrm{aq})$ are available particularly regarding the electrodissolution of the metal and its passivation $[10,11,14-16]$. Therefore, it is worthwhile to attempt now to correlate the electrochemical and physicochemical variables which are responsible for the periodic oscillation of either the current under potentiostatic conditions or the potential under galvanostatic conditions $[17,18]$. In this respect most of the qualitative data reported in the literature refer to concentrated $\mathrm{HCl}$ solutions [17]. The model proposed then for the periodic oscillation of the current at a constant external potential is fundamentally based upon the concentration polarization contribution [19], a situation which is approached when the $\mathrm{HCl}$ concentration exceeds a limiting value.

\section{EXPERIMENTAL}

The experimental arrangement was practically the same previously described[20]. The Au working electrode consisted of a gold disc $\left(0.125 \mathrm{~cm}^{2}\right)$ embedded in a PTFE holder to be used either still or under rotation. The surface preparation of the disc surface before each run consisted of a mechanical polishing initiated with 600 mesh emery paper to finish with a mirror surface using the finest alumina powders. The potential of the working electrode was measured against a sce although in the text all potentials are given in the nhe scale. The counterelectrode was a Pt sheet (about $10 \mathrm{~cm}^{2}$.

The solutions were made from AR chemicals and triple distilled water. The following solutions were used: (i) $0.5 \mathrm{~N} \mathrm{HCl} ; 0.75 \mathrm{~N} \mathrm{HCl} ; 1.0 \mathrm{~N} \mathrm{HCl} ; 1.5 \mathrm{~N} \mathrm{HCl}$ and $2 \mathrm{~N} \mathrm{HCl}$; (ii) $0.5 \mathrm{~N} \mathrm{HCl}+0.5 \mathrm{~N} \mathrm{KCl} ; 0.75 \mathrm{~N} \mathrm{HCl}$ $+0.5 \mathrm{~N} \mathrm{KCl}$; (iii) $1.5 \mathrm{~N} \mathrm{H}_{2} \mathrm{SO}_{4}$; (iv) $1.5 \mathrm{~N} \mathrm{H}_{2} \mathrm{SO}_{4}+$ $0.01 \mathrm{~N} \mathrm{HCl} ; 1.5 \mathrm{~N} \mathrm{H}_{2} \mathrm{SO}_{4}+0.05 \mathrm{~N} \mathrm{HCl} ; 1.5 \mathrm{~N}$ $\mathrm{H}_{2} \mathrm{SO}_{4}+0.25 \mathrm{~N} \mathrm{HCl} ; 1.5 \mathrm{~N} \mathrm{H}_{2} \mathrm{SO}_{4}+0.60 \mathrm{~N} \mathrm{HCl}$. The runs were made in the range $25-50^{\circ} \mathrm{C}$ under a continuous purified $\mathrm{N}_{2}$ atmosphere.

Potentiostatic $E / I$ curves were previously recorded to establish the active to passive transition potential range of the different solutions, either with the still disc electrodes or under rotation in the range $168-1000 \mathrm{rev}$ $\min ^{-1}$. The chosen potential step $\left(E_{s}\right)$ corresponded to the minimum potential required to produce the oscillating current. The potential step was applied as indicated elsewhere[20] and the current/time records were displayed on a fast Fsterline-Angus recorder.

\section{RESULTS}

\section{General characteristics of the oscillating current}

In solutions containing only $1.5 \mathrm{~N} \mathrm{H}_{2} \mathrm{SO}_{4}$ the potentiostatic $E / I$ curve shows that passivation sets in when the potential exceeds $1.590 \mathrm{~V}$, then the residual passivity current is independent on stirring. For a rde, no effect is observed between 100 and $1000 \mathrm{rev} \mathrm{min}^{-1}$. Contrarily, when $\mathrm{HCl}$ is added to approx. $0.01 \mathrm{~N}$, the passivity current although still keeps a low value it starts to depend on the stirring conditions.

In still solutions the periodic current oscillations are produced only when the $\mathrm{HCl}$ concentration exceeds a certain threshold and the potential step is comprised within a relatively narrow potential range. Thus, the $\mathrm{Au} / 1.5 \mathrm{~N} \mathrm{H}_{2} \mathrm{SO}_{4}+0.05 \mathrm{~N} \mathrm{HCl}$ is potentiostatted at $E_{s}=1.511 \mathrm{~V}$ a smooth periodic current oscillation at 




Fig. 1. Current/time display $2 \mathrm{~N} \mathrm{HCl,} E_{\mathrm{g}}: 1.712 \mathrm{Y}, 25^{\circ} \mathrm{C}$.

$1 / 16 \mathrm{~Hz}$ is observed. On increasing the $\mathrm{HCl}$ concentration to $0.25 \mathrm{~N}$ at $E_{s}=1.552 \mathrm{~V}$, the current oscillation frequency is $1 / 5 \mathrm{~Hz}$ and for a mixture containing $0.6 \mathrm{~N} \mathrm{HCl}$, the frequency is $1 / 3.45 \mathrm{~Hz}$. Each period (Fig. 1) roughly involves a lapse of large anodic current $\left(t_{d}\right)$ which is called the active region and a lapse of relatively low current $\left(t_{p}\right)$ which is called the passivation region. As an example, for the $1.5 \mathrm{~N}$ $\mathrm{H}_{2} \mathrm{SO}_{4}+0.6 \mathrm{~N} \mathrm{HCl}$ solution $t_{d}=0.80 \mathrm{~s}$ and $t_{\mathrm{p}}=2.65 \mathrm{~s}$. Apparently the current fluctuation is easier to establish if soluble Au species are initially present in solution.

The potential at which the periodic current oscillations are produced with the still solutions correspond to the potential range where a limiting current $\left(I_{\mathrm{lim}}\right)$ is observed with the stirred solutions. At low rotation speeds $(\omega)$ the limiting current approaches a linear dependence with the square root of $\omega$ (Figs 2 and 3) and the slope of the $I_{\text {IIm }}$ os $\omega^{1 / 2}$ plot increases linearly with the $\mathrm{HCl}$ concentration. At high rotation speeds, however, apparently a rate independent of $\omega$ is ap proached. The periodic current oscillations produced with the still solutions disappear immediately on stirring.

The morphology of the anodized substrate changes accordingly with the solution composition. The periodic effect is associated with a localized type of corrosion. After anodizing the $\mathrm{Au} / 1.5 \mathrm{~N} \mathrm{H}_{2} \mathrm{SO}_{4}$ system at potentials within the range of the passivity potential the surface metal results covered with a relatively thin dull and dark deposit which as revealed by $\mathrm{X}$-ray diffractometry corresponds to the $\mathrm{Au}_{2} \mathrm{O}_{3}$ structure. On the other side, after anodizing the $\mathrm{HCl}$ containing solutions, the metal surface comes out completely electropolished to a mirror surface. In the case of the rde the electrode surface exhibits the characteristic map of curved radial lines[21].

\section{Characteristics of the oscillating I/time profile}

The frequency of the oscillating current depends principally on the solution composition and stillness and on the perturbation potential $\left(E_{s}\right)$. Once the periodic effect sets in (Fig. 1) the $I /$ time profile obtained for the different solutions exhibit common characteristics. The active region lasting during $t_{\mathrm{d}}$ presents an abrupt initial current jump to attain a current peak. Afterwards the current decays relatively smoothly down to the time $t_{d}$ from the initiation of the cycle. At $t_{d}$ a sharp current decrease is seen. The passive region time $\left(t_{\mathrm{p}}\right)$ is equal to the difference $t_{T}-t_{\mathrm{d}}$.

For each particular solution both $t_{p}$ and $t_{d}$ depend on $E_{s}$. When $E_{s}$ increases, $t_{d}$ decreases slightly but $t_{p}$ increases appreciably (Table 1 ). The potential threshold $\left(E_{s}\right)$ depends on the solution composition. When the interface is perturbed with the $E_{s}$ potential step then $t_{d}$ decreases as the $\mathrm{HCl}$ concentration increases (Table 2). The current oscillations earlier recorded in the $\mathrm{Au} / 4 \mathrm{~N} \mathrm{HCl}$ system by other au-

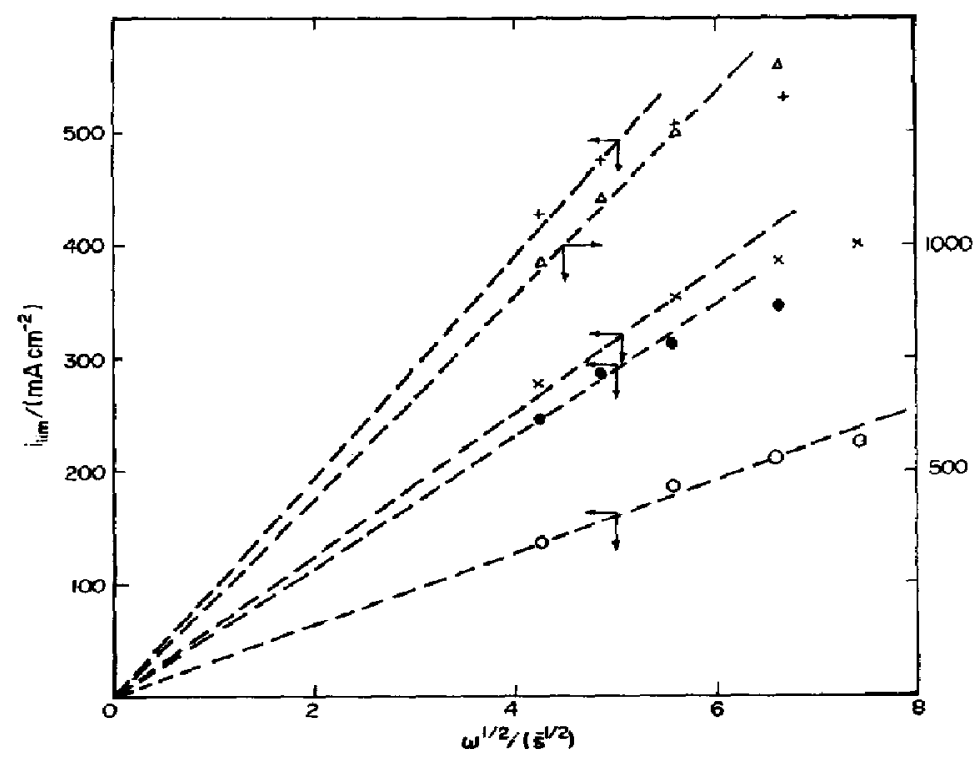

Fig. 2. Dependence of $i_{L}$ on $\omega^{1 / 2}$ at difierent concentrations, $25^{\circ} \mathrm{C}$. (O) $0.5 \mathrm{~N} \mathrm{HCl},(\mathrm{O}) 0.75 \mathrm{~N} \mathrm{HCl},(\times) 0.5 \mathrm{~N}$ $\mathrm{HCl}+0.5 \mathrm{~N} \mathrm{KCl} ;(+) 0.75 \mathrm{~N} \mathrm{HCl}+0.5 \mathrm{~N} \mathrm{KCl} ;(\Delta) 3 \mathrm{~N} \mathrm{HCl}$. 


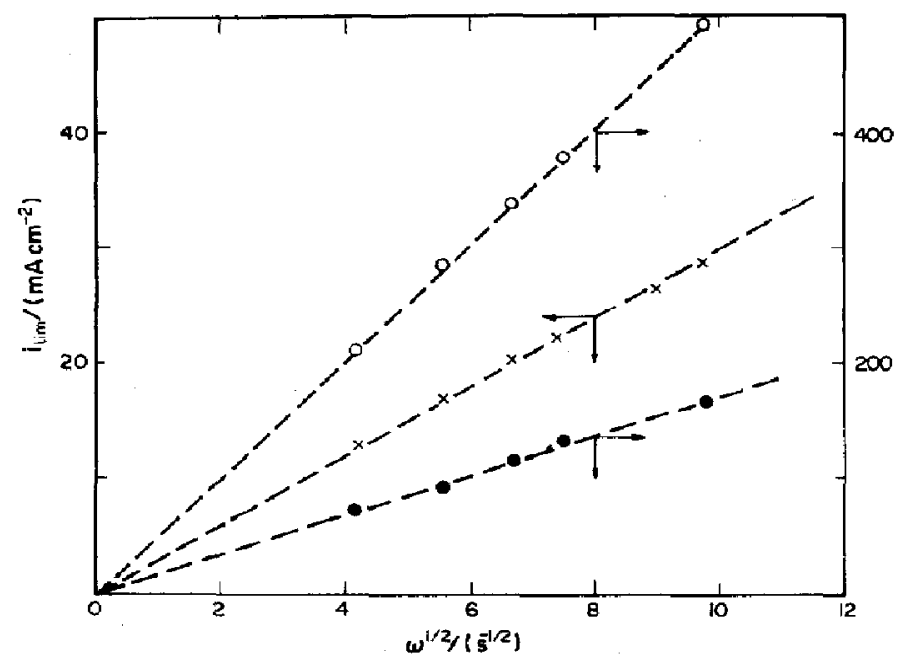

Fig. 3. Dependence of $i_{L}$ on $\omega^{1 / 2}$ at different $\mathrm{HCl}$ concentrations in $1.5 \mathrm{~N} \mathrm{H}_{2} 5 \mathrm{SO}_{4}$ solutions. $(\times) 0.05 \mathrm{~N} \mathrm{HCl}$, (O) $0.25 \mathrm{~N} \mathrm{HCl},(\mathrm{O}) 0.59 \mathrm{~N} \mathrm{HCl} .25^{\circ} \mathrm{C}$.

thors [17] are in good correspondence with the $I / t$ characteristics reported here for the more diluted $\mathrm{HCl}$ solutions.

The height of the current peak $\left(I_{M}\right)$ observed at $t_{M}$, increases linearly with the $\mathrm{HCl}$ concentration. Otherwise, the residual current recorded in the passive region slightly decreases when the $\mathrm{HCl}$ concentration increases. The charge involved in the active region is comparatively larger than that of the passive region. Nevertheless, in any case the net faradaic processes yield the electrodissolution of the metal during the periodic fluctuation of the current. The charge related to the passive region is always much larger than that of an oxygen monolayer formed on gold based on the $\mathrm{Au}_{2} \mathrm{O}_{3}$ stoichiometry. It should correspond to an oxide film of $50-80 \AA$ thickness. According to measurements reported by other authors the composition of the film should correspond to gold hydroxide with some occluded water[2].

Under the $E_{s}$ potential step the oscillation frequency $(f)$ defined as the inverse of the period time $(T)$, increases linearly on the $\mathrm{HCl}$ concentration. The temperature dependence of the frequency fits an Arrhenius plot with an experimental activation energy equal to $3.9 \mathrm{kcal} / \mathrm{mol}$ (Fig. 4).

\section{INTERPRETATION AND DISCUSSION}

Previously reported data have shown that the passivity potential $\left(E_{p}\right)$ of the $\mathrm{Au} / \mathrm{HCl}(\mathrm{aq})$ interface, at

Table 1. Values of $t_{d}$ and $t_{p}$ at different $E_{s} .1 .5 \mathrm{~N} \mathrm{H}_{2} \mathrm{SO}_{4}+$ $0.60 \mathrm{~N} \mathrm{HCl}$ at $25^{\circ} \mathrm{C}$

\begin{tabular}{ccc}
\hline $\begin{array}{c}E_{\mathrm{s}} \\
(\mathrm{V})\end{array}$ & $\begin{array}{c}t_{\mathrm{d}} \\
(\mathrm{s})\end{array}$ & $\begin{array}{c}t_{\mathrm{p}} \\
(\mathrm{s})\end{array}$ \\
\hline 1.592 & 1.4 & 2.0 \\
1.596 & 2.0 & 3.2 \\
1.600 & 2.3 & 6.0 \\
1.602 & 2.5 & 8.1 \\
1.606 & 3.9 & 14.8 \\
\hline
\end{tabular}

$25^{\circ} \mathrm{C}$, depends on the acid concentration according to the following equation $[14,16]$ :

$$
E_{p}=1.630+2.303 \frac{R T}{F} \log C_{\mathrm{HCl}} .
$$

The potential required for producing the oscillating current depends in principle on the $\mathrm{HCl}$ concentration as predicted by (1). Since the reversible potential of the $\mathrm{Au} / \mathrm{Au} \mathrm{Cl} \mathrm{Cl}^{-}$couple, at $25^{\circ} \mathrm{C}$, is $1.154 \mathrm{~V}$ [22] the establishment of the oscillating current involves a large polarization of the interface.

The electrochemical characteristics of the $\mathrm{Au} / \mathrm{HCl}(\mathrm{aq})$ interface in the potential range pertaining to the electrodissolution of the metal are related to the following overall reactions[16]:

$$
\mathrm{Au}+2 \mathrm{Cl}^{-}=\mathrm{AuCl}_{2}^{-}+e
$$

and

$$
3 \mathrm{AuCl}_{2}^{-}=\mathrm{AuCl}_{4}^{-}+2 \mathrm{Au}+2 \mathrm{Cl}^{-} .
$$

Reaction (2) is followed by a heterogeneous equilibrium represented by reaction (3). Reaction (2) is a relatively fast electrochemical process which under the usual perturbation conditions is under diffusion control. In the present case, this is confirmed by the dependence of $I_{M}$ on the $\mathrm{HCl}$ concentration and from the effect of stirring on the periodic effect. Therefore, as

Table 2. Values of $t_{d}$ and $t_{p}$ at different $\mathrm{HCl}$ concentrations. $25^{\circ} \mathrm{C}$

\begin{tabular}{cccccc}
\hline $\begin{array}{c}C_{\mathrm{HC} 1} \\
(\mathrm{~N})\end{array}$ & $\begin{array}{c}E_{z} \\
(\mathrm{~V})\end{array}$ & $\begin{array}{c}t_{d} \\
(\mathrm{~s})\end{array}$ & $\begin{array}{c}t_{p} \\
(\mathrm{~s})\end{array}$ & $\begin{array}{c}f \\
(\mathrm{~Hz})\end{array}$ & $\begin{array}{c}E_{p} \text { (from (1)) } \\
(\mathrm{V})\end{array}$ \\
\hline 0.50 & 1.600 & 11.0 & 12.6 & 0.042 & 1.628 \\
1.00 & 1.630 & 7.10 & 15.0 & 0.045 & 1.630 \\
1.50 & 1.642 & 5.5 & 13.4 & 0.053 & 1.641 \\
2.00 & 1.712 & 3.7 & 2.2 & 0.169 & 1.648 \\
$4.00^{*}$ & $1.800^{*}$ & - & - & - & 1.666 \\
\hline
\end{tabular}

* Data taken from [17]. 
reaction (2) proceeds, a decrease of the $\mathrm{HCl}$ concentration at the interface should occur. Then, the characteristics of the current in the active region are mainly diffusion controlled. It is worthwhile to note that the number $(z)$ of electrons per mole of reacting $\mathrm{Cl}^{-}$ion at the interface goes from 0.5 to 0.75 depending on the extent of contribution of reaction (3). The value derived from voltammetry for $z$ is 0.66 . This figure is used to obtain the diffusion coefficient of the reacting species from the $I_{\lim } v s \omega^{1 / 2}$ plots from those solutions containing an excess of supporting electrolyte (Fig. 2), using Levich's equation[21] and the proper viscosity and density of each solution. At $25^{\circ} \mathrm{C}$ the calculated diffusion coefficient $\left(D=1.2 \times 10^{-s} \mathrm{~cm}^{2} / \mathrm{s}\right)$ coincides with the one already reported[16]. In spite of the diffusion kinetic contribution in the active region other facts are relevant for interpreting the oscillating current effect. It is well established that $\mathrm{Cl}^{-}$ion adsorbs specifically on gold $[13,16]$ and that the metal electrooxidation through the complex ion formation implies the appearance of bare metal surface where the electroformation of an oxygen containing layer takes place. The potential threshold for the latter reaction which initiates through the discharge of water molecules $[10,11]$ is slightly higher than that of the $\mathrm{Cl}^{-}$ ion discharge, at least for $\mathrm{HCl}$ concentrations larger than $10^{-3} \mathrm{M}$. Therefore, the oxide layer electroformation process becomes possible if chloride ions at the surface are used up faster than they are replenished by diffusion. The electroformation of the oxide layer on the metal plays an important role in the establishment of the oscillating current. As far as the $\mathrm{HCl}$ concentration at the interface is kept high enough to prevent the water discharge, as in the case of stirring, no periodic current oscillations set in.

The analysis of the $1 /$ time display of each period furnishes interesting information about the corresponding rate processes. Thus, in the active region the smooth current decay zone fits a linear $I / t^{-1 / 2}$ relationship as one finds for a simple linear diffusion fast electron transfer reaction involving soluble species occurring under a potentiostatic step[23]. But the current peak, which is undoubtedly related to a diffusion of the $\mathrm{HCl}$ species, is beyond the simple diffusion model and indicates the contribution of the oxide dissolution process. Thus, during each period the initiation of the active region comprises a metal surface which goes from its complete coverage to a practically bare metal surface. The oxide dissolution process yielding the uncovered metal surface, depends on the local $\mathrm{HCl}$ concentration. The latter at the end of the passive region reached practically the bulk concentration value.

The film dissolution process may occur either uniformly or non-uniformly. If the film dissolves uniformly the covered to uncovered area transition in the limiting case is stepwise. But this possibility seems unlikely because of the three-cimensional structure of the film formed during passivation. Uader these circumstances the oxide film may dissolve locally so that the bare metal regions spread laterally. Then, the chloride ion concentration distribution at the surface will be non-uniform, the area first activated may already passivate before the surface activation is alt over. The situation thus corresponds to a dissipative space structure described by thermodynamics [24] and is reflected through the type of localized corrosion associated to the periodic phenomena. Therefore, the kinetics should be locally described by a system of coupled differential equations. The integration of the local current density over the surface should give the resulting current.

On the other hand, the initiation of each period can be expressed through a simple average diffusion model involving an average time-dependent electrode surface area. Thus, the equation for the diffusion controlled

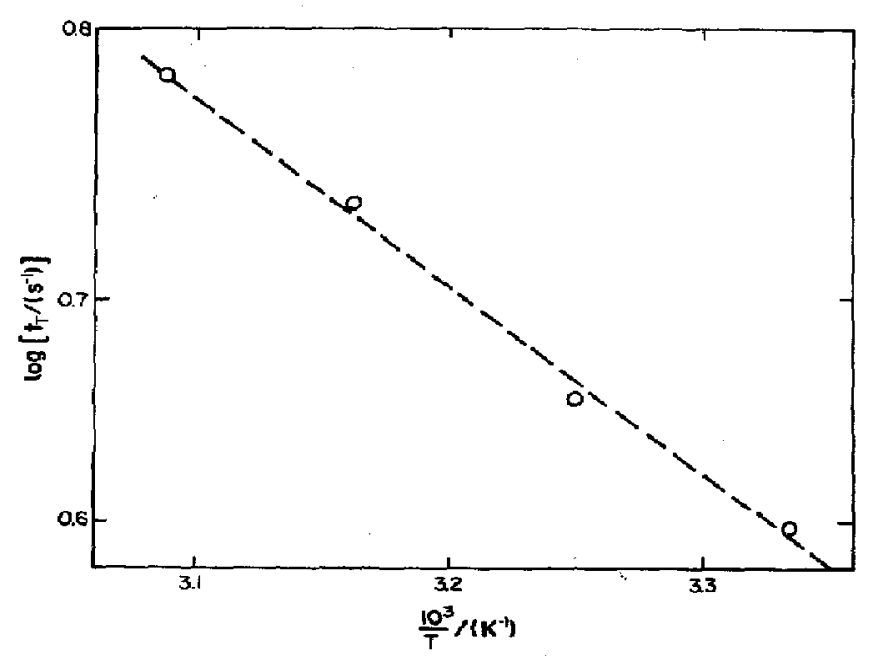

Fig. 4. Arrhenius plot for the current oscitlation frequency. $1 \mathrm{~N} \mathrm{HCl}$. 


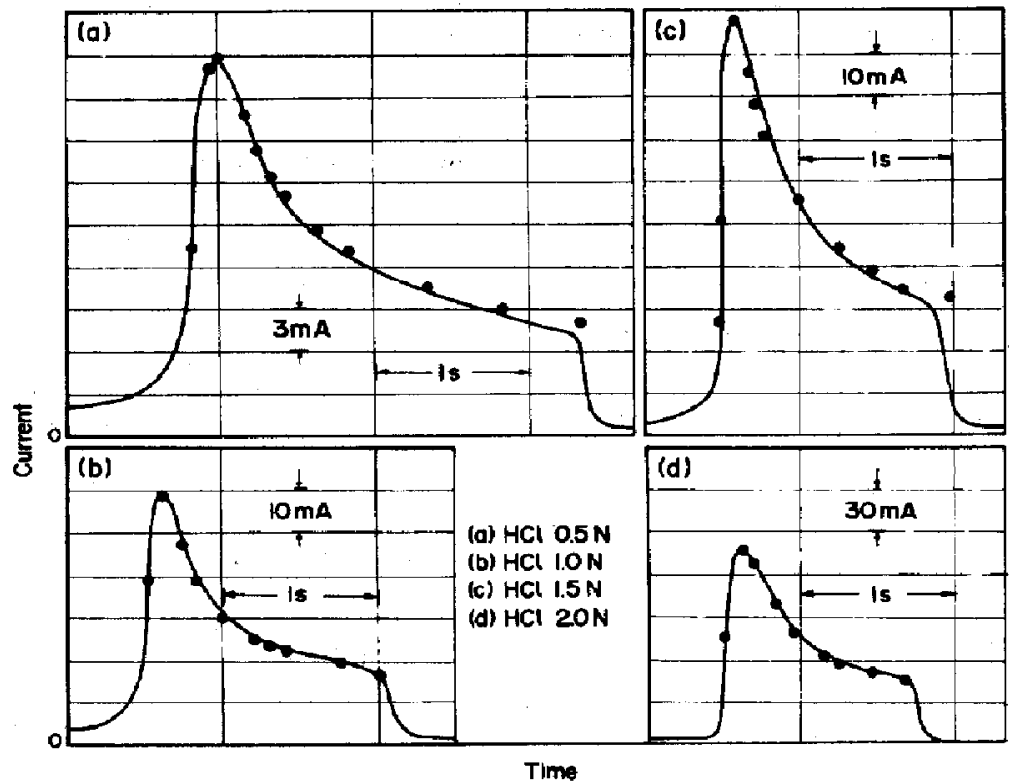

Fig. 5. Current/time displays at different $\mathrm{HCl}$ concentrations at $25^{\circ} \mathrm{C}$. Points calculated from (6) with different $k_{d}$ values : (a) $k_{d}=10 \mathrm{~s}^{-1}$, (b) $k_{d}=20 \mathrm{~s}^{-1}$, (c) $k_{d}=20.5 \mathrm{~s}^{-1}$ and (d) $k_{d}=40 \mathrm{~s}^{-1}$.

fast process involving soluble species can be written as the product of two independent terms one containing the changing area and another containing the rest of the terms:

$$
\left\langle I_{a}\right\rangle=z F\langle A\rangle \frac{D^{1 / 2} C_{\mathrm{HCl}}^{\circ}}{(\pi t)^{1 / 2}}
$$

where $\left\langle I_{a}\right\rangle$ denotes the average diffusional anodic current, $z$ is the charge entering the reaction per mole of reacting species $C_{\mathrm{HCl}}^{\circ}$ is the bulk $\mathrm{HCl}$ concentration and $D$ is the diffusion coefficient of $\mathrm{Cl}^{-}$ion. $\langle A\rangle$ is the average value of the time dependent bare metal area. Equation (4) implies the occurrence of two inde- pendent processes, namely the chemical dissolution of the oxide layer and the electrooxidation of the metal through the chloro-gold-complex species. To evaluate $\langle A\rangle$ one further assumes that the passivity disappears on the average surface by a first order chemical dissolution, according to:

$$
\frac{\mathrm{d} A}{\mathrm{~d} t}=k_{d}(1-A),
$$

where $k_{d}$ stands for the formal average first order rate constant of the dissolution process and $(1-A)$ corresponds to the fraction of the oxide covered electrode surface. After integration of (5), taking into account the

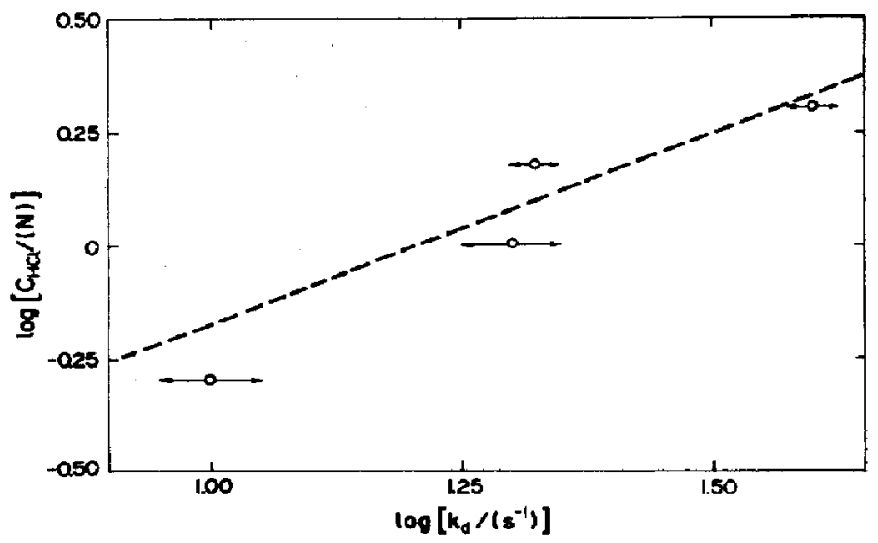

Fig. 6. Dependence of $k_{\text {d }}$ on $\mathrm{HCl}$ concentration. 
following boundary conditions $t=0, A=0$ and $t=t_{M}$, $A=1$, and replacing the solution into (4), one obtains:

$$
\left\langle I_{a}\right\rangle=K \frac{\left(1-\mathrm{e}^{-k_{s}}\right)}{t^{1 / 2}},
$$

where $K$ contains the rest of the terms of (4). By adjusting the $k_{\mathrm{d}}$ value, (6) reproduces reasonably well the $I /$ time profiles (Fig. 5). At constant ionic strength $k_{d}$ depends linearly on the $\mathrm{HCl}$ concentration (Fig. 6). Within the concentration range covered by the present work $k_{d}$ also depends on the total ionic composition of the solution as it should be expected for this type of reactions. During the active region, the $\mathrm{Cl}^{-}$ions are progressively replaced by the complex $A u(I)$ and Au(III) ions yielded by reactions (2) and (3) and its concentration at the interface decreases according to (6). Therefore when the concentration of $\mathrm{Cl}^{-}$ion at the electrode surface becomes zero the discharge of water and the initiation of the passive region are feasible. The corresponding faradaic processes imply the progressive coverage of the surface with an oxide layer of increasing thickness. The anodic current in the passive region is then small. The film formation takes place simultaneously with the slow but continuous back diffusion of $\mathrm{HCl}$ towards the interface.

At the very beginning of the passive region, the formation of the oxide monolayer involve a charge density including an unknown roughness factor of the order of $0.4 \mathrm{mC} / \mathrm{cm}^{2}$. The kinetics of this process is already fairly well established in acid solutions [5-12]. The rest of the anodic charge involved up to time $T$ corresponds to the thickening of the oxide layer. The current decrease at the initiation of the oxide thickening when the $\mathrm{HCl}$ concentration at the interface is still low so that the chemical dissolution of the film can be ignored, approaches a linear $I / \log t$ relationship as usually found for different mechanisms related to the potentiostatic growth of oxide film[25]. Under the present circumstances working at a constant potential which is lower than that for oxygen evolution the contribution of the "blister" mechanism for the film growth in the passive region is likely negligible[2]. Once the acid concentration at the interface is replenished by back diffusion, the oxide film is dissolved. Thus, the sequence of processes are repeated. The periodic phenomena lasts until no more available metal exists. Therefore, the two electrochemical processes are coupled to the diffusion and chemical dissolution processes. The different rate constants of these processes originate the bi-stability of the electrochemical system [26]. Therefore, the electrochemical characteristics of the periodically oscillating current are justly one example which approaches better than other systems the model for the electrochemical oscillations proposed by Degn[19] consisting of an external resistance, a current/potential curve with a negative slope and a concentration polarization term.

These results also handle further support to the participation of a competitive adsorption between $\mathrm{Cl}^{-}$ ion and $\mathrm{OH}^{-}$containing species in the dissolution and passivation of $\mathrm{Au}$ in $\mathrm{HCl}$ containing solutions.

Acknowledgement - INIFTA is sponsored by the Consejo Nacional de Investigaciones Cientificas y Técnicas, the Universidad Nacional de La Plata and the Comisión de Investigaciones Cientificas (Provincia de Buenos Aires). This work is also partially sponsored by the SENID (Navy Research and Development Service of Argentina) and the Regional Program for the Scientific and Technological Development of the Organization of the American States.

\section{REFERENCES}

1. J. P. Hoare, The Electrochemistry of Oxygen, Chs 2 and 3. Interscience, New York (1968).

2. S. Barnartt, J. electrochem. Soc. 106, 722 (1959).

3. J. L. Whitton and J. A. Davies, J. electrochem. Soc. 111, 1347 (1964).

4. G. M. Schmid and M. E. Curley-Fiorino, Encyclopedia of Electrochemistry of the Elements, (Edited by A. J. Bard), Vol. IV, Ch. 3. Dekker, New York (1975).

5. D. A. J. Rand and R. Woods, J. electroanal. Chem. 35, 209 (1972).

6. S. H. Cadlc and S. Bruckenstcin, Analyt. Chem. 4, 2225 (1972).

7. K. Moslavac, B. Lovrecek and R. Radeka, Electrochim. Acta 17, 414 (1972).

8. Y. Y. Vinnikov, V. A. Shepelin and V. I. Veselovskii, Soviet Electrochem. 8, 1201 (1972).

9. S. H. Cadle and S. Bruckenstein, J.electroanal. Chem.48, 325 (1973).

10. C. M. Ferro, A. J. Calandra and A. J. Arvía, J. electroanal. Chem. 50, 403 (1974).

11. C. M. Ferro, A. J. Calandra and A. J. Arvía. J. electroanal. Chem. 55, 291 (1974).

12. D. Dickertmann, J. W. Schultze and K. J. Vetter, J. electroanal. Chem. 55, 429 (1974).

13. R. P. Frankenthal and D. E. Thompson, J. electrochem. Soc. 123, 799 (1976).

14. T. Heumann and H. S. Panesar, Z. phys. Chem. 229, 84 (1965).

15. J. N. Gaur and G. M. Schmid, J. electroanal. Chem. 24, 279 (1970).

16. J. Herrero Gallego, C. E. Castellano, A. J. Calandra and A. J. Arvia, J. electroanal. Chem. 66, 207 (1975).

17. U. F. Franck, Z. Elektrochem. 62, 649 (1958).

18. K. Vetter, Electrochemical Kinetics. Academic Press, New York (1967)

19. H. Degn, Trans. Faraday Soc. 64, 1348 (1968).

20. J. J. Podestá, R. C. V. Piatti and A. J. Arvía, J. electrochem. Soc. (in press).

21. B. Levich, Physicochemical Hydrodynamics. PrenticeHall, Englewood Cliffs, New Jersey (1962).

22. J. J. Lingane, J. electraanal. Chem. 4, 332 (1962).

23. P. Delahay, New Instrumental Methods in Electrochemistry. Interscience. New York (1966).

24. P. Glansdorff and I. Prigogine, Thermodynamic Theory of Structure, Stability and Fluctuations, pp. 222-272. Wiley-Interscience, London (1971).

25. E. Gileadi, Electrosorption. Plenum Press, New York (1967).

26. U. F. Franck, Faraday Symp. chem. Soc. 9, 137 (1974). 